\title{
Kus tegijaid, seal nägijaid? Akadeemilise prokrastineerimise õpetajapoolse märkamise seosed õpilaste individuaalsete erinevustega
}

\author{
Kati Aus $^{\text {al }}$, Grete Arro ${ }^{a}$, Anna-Liisa Jõgi ${ }^{\text {ab }}$, Elina Malleus ${ }^{a}$ \\ a Tallinna Ülikooli psühholoogia instituut \\ ${ }^{b}$ Tallinna Ülikooli kasvatusteaduste instituut
}

\begin{abstract}
Annotatsioon
Algkoolist põhikooli liikudes muutub õpitav keerulisemaks ja abstraktsemaks. Õpilaste eneseregulatsioonioskus ja selle arengu toetamine on seetõttu vaieldamatult olulised. Üks teadaolev eneseregulatsiooniprobleem on õpikohustuste täitmise edasilükkamine ehk akadeemiline prokrastineerimine. Prokrastineerimiskäitumine võib välja kujuneda juba põhikoolis, kuid jääda õpetajatele seejuures märkamata. Siinses uurimuses võrdlesime 8 . klasside õpilaste $(N=551)$ hinnanguid oma prokrastineerimiskäitumisele kolme aineõpetaja $(N=118)$ hinnangutega. Leidsime, et õpilaste ja õpetajate hinnangud ei lange alati kokku ning õpetajad näevad prokrastineerijatena pigem vähem võimekaid õpilasi, olenemata sellest, kas õpilane ise peab end prokrastineerijaks või mitte. Samuti tõid õpetajad prokrastineerijatena esile pigem keskmisest ekstravertsemaid lapsi. Et uurida, kas õpetaja vaatevälja jäämiseks on olulisemad pigem õpilaste isiksuseomadused või vaimne võimekus, pöörasime eraldi tähelepanu neile õpilastele, kes on endi sõnul sagedased prokrastineerijad. Leidsime, et mida võimekam on õpilane olnud juba algklassides ning mida introvertsem 7. klassis, seda väiksem on tõenäosus, et õpetajad tema prokrastineerimiskalduvust 8. klassis märkavad. Tulemused lubavad järeldada, et õpetajatel on raske tuvastada võimekamate ja introvertsemate õpilaste eneseregulatsiooniprobleeme. Õpetajad peaksid peale ainealaste õpitulemuste hindamise pöörama kindlasti tähelepanu ka õpilaste õpioskuste süstemaatilisele hindamisele.
\end{abstract}

Võtmesõnad: akadeemiline prokrastineerimine, õpioskused, õpetajate hinnangud õpioskustele, vaimne võimekus, isiksus

1 Psühholoogia instituut, Tallinna Ülikool, Narva mnt 29, 10120 Tallinn; katiaus@tlu.ee 


\section{Sissejuhatus}

Prokrastineerimine ehk kohustuste irratsionaalne edasilükkamine tuleneb erinevate ingliskeelsete veebisõnastike (nt Merriam-Websteri) andmetel ladinakeelsest sõnast procrastinare (pro 'edasi' + crastinus 'homsesse kuuluv'). See on levinud väljend, kuid leidub riike, nagu Madalmaad, Peruu ja Eesti, kus prokrastineerimine sõnana on veel suhteliselt tundmatu. Sellegipoolest on prokrastineerimine kui käitumismall Eestis tõenäoliselt sama levinud kui nt Põhja-Ameerikas, kust pärineb enamik selleteemalisi uurimusi.

Prokrastineerimise ajaloolist tausta uurides on leitud, et tööstusrevolutsiooni alguseni ehk ligikaudu 18. sajandi keskpaigani ei olnud sellel mõistel negatiivset varjundit (Steel, 2010). Ka tänapäeval viitavad inimesed sageli oma edasilükkamiskäitumisele põhjendusi otsides prokrastineerimisega kaasneva viimase hetke energialaengu positiivsele mõjule (Grunschel, Patrzek, \& Fries, 2013). Uurimused prokrastineerimise positiivset mõju siiski ei toeta. Prokrastineerimist peetakse kirjanduses ebakohaseks ja irratsionaalseks harjumuseks, mis pärast kohustuse edasilükkamisega kaasnevat positiivset kergendust viib pikemas perspektiivis kehvema toimetulekuni nii akadeemilises tegevuses kui ka töös ning negatiivsete enesekohaste mõtete, süütunde, stressi ja teatud juhul koguni stressist tingitud terviseprobleemideni (Sirois, 2007; Steel, 2007; Steel \& Ferrari, 2013; Tice \& Baumeister, 1997; van Eerde, 2003).

Prokrastineerimist eristatakse ajaplaneerimisest või lihtsalt viivitamisest ja venitamisest, sest prokrastineerimise definitsioon on laiem ja sisaldab endas alati motivatsioonilist konflikti (Paulitzki, 2010). Kui tahtlikku viivitamist võib pidada mõistlikuks ajakasutamiseks, siis prokrastineerimise määratluses peaks varasematele uurimustele tuginedes sisalduma vähemasti kolm peamist kriteeriumi: a) hinnatav käitumine on seotud mõne tegevuse või otsuse edasilükkamisega, b) edasilükkamine on mittekavatsuslik ning c) see halvendab sooritust või on kahjulik (Milgram, Marshevsky, \& Sadeh, 1995; Paulitzki, 2010; Steel, 2007). Lisaks on Milgram jt (1995) toonud esile prokrastineerimise emotsionaalse aspekti, mistõttu võiks määratluses sisalduda ka edasilükatava kohustuse subjektiivne olulisus ja kohustuse täitmata jätmisega kaasnev emotsionaalne ebamugavustunne. Steel (2007) rõhutab omalt poolt prokrastineerimise irratsionaalsust: inimesed viivitavad tegevustega, kuigi teavad, et edasilükkamine ei too neile kokkuvõttes kasu. Irratsionaalsuse kõrval on prokrastineerimiskäitumise juures tähtsal kohal ka viivitamise tahtmatu olemus. Prokrastineerijatel on raskusi oma kavatsuste ja plaanide 
elluviimisel, mistõttu võib prokrastineerimist pidada irratsionaalseks ja tahtmatuks ennast kahjustavaks käitumiseks, mida võib käsitleda eneseregulatsiooniprobleemina (Steel, 2007).

\section{Akadeemiline prokrastineerimine}

Akadeemiline prokrastineerimine on igapäevaeluliste toimetustega ja otsuste langetamisega seotud prokrastineerimise kõrval kõige enam levinud prokrastineerimise vorm (Milgram, Mey-Tal, \& Levison, 1998). Akadeemilise prokrastineerimise kohta puudub ühtselt kokku lepitud määratlus (Schraw, Wadkins, \& Olafson, 2007), kuid see võiks sisaldada kavatsust täita akadeemiliseks edasijõudmiseks vajalikud kohustused õigel ajal ning kohustuste edasilükkamist, hoolimata nende prioriteetsusest (Lay, 1986, 1994). Akadeemilist prokrastineerimist on laialdaselt ja väga erinevate meetoditega uuritud tudengite (Ferrari \& Pychyl, 2012; Milgram, Dangour, \& Ravi, 1992; Rabin, Fogel, \& Nutter-Upham, 2011; Solomon \& Rothblum, 1984) ning pisteliselt põhikooliõpilaste hulgas (vt nt Klassen et al., 2009; Liu, 2009). Meile teadaolevalt on kõik senini tehtud uurimused olnud peamiselt ristlõikelised, keskendudes prokrastineerimiskäitumise hindamisele kõige pikemalt ühe akadeemilise semestri jooksul (Rothblum, Solomon, \& Murakami, 1986; Tice \& Baumeister, 1997). Seetõttu ei võimalda need mõista prokrastineerimiskäitumise arengulist tausta.

\section{Akadeemilise prokrastineerimise põhjused}

Prokrastineerimist seostatakse erinevate isiku- ja ülesandepõhiste teguritega. Inimesed, kes prokrastineerivad, on teistest keskmiselt impulsiivsemad. Neil on raske mitte järele anda ülesannete edasilükkamisega kaasnevale hetkelisele kergendustundele ja keskenduda ülesande täitmisest tulenevatele pikaajalistele kasudele (DeWitte \& Schouwenburg, 2002; Steel, 2007). Wendelien van Eerde (2003) tehtud metaanalüüsi tulemused kinnitavad, et isiksuseomadustest on prokrastineerimine kõige tugevamalt seotud meelekindluse dimensiooniga - mida meelekindlam on inimene, seda vähem kipuvad tal kohustused viimasele hetkele kuhjuma. Howell koos kolleegidega (2006) on näidanud, et prokrastineerijad kipuvad alahindama ajaliselt kaugele tulevikku jäävate tasude või karistuste (nt hea hinde, eksamil läbikukkumise) olulisust. Mida lähemale tasu või karistus ajaliselt jõuab ehk mida käegakatsutavamaks see muutub, seda enam kasvab prokrastineerija töö hulk. Seetõttu on prokrastineerijatele omased viimasel hetkel tehtavad üleloomulikud pingutused kohustuste õigeaegseks täitmiseks (Howell, Watson, Powell, \& Buro, 2006). Ka DeWitte ja 
Schouwenburg (2002) juhivad tähelepanu asjaolule, et ehkki prokrastineerijatel on teistest raskem ära öelda planeeritud töid ja tegemisi häirivatele sotsiaalsetele segajatele (nt sõbrad, meedia, sotsiaalmeedia), ei tee nad kokkuvõttes teistest vähem tööd, kuid teevad seda sageli väga intensiivselt viimasel hetkel. Motivatsioonitegurite kontekstis iseloomustavad prokrastineerijaid pigem vähene enesetõhusus ja ebaõnnestumise vältimisele suunatud akadeemilised eesmärgid (Wolters, 2003). Prokrastineerimiskäitumise uurimustes on senini vähe tähelepanu pööratud kognitiivsele võimekusele. Senised ristlõikeliste uurimuste tulemused ei näita olulisi seoseid üldise kognitiivse võimekuse ja prokrastineerimise vahel: prokrastineerijaid leidub nii võimekate kui ka vähem võimekate hulgas (Ferrari, 2000).

Prokrastineerimiskäitumise seletamine vaid isikupõhiste tunnuste kaudu ei ole muidugi piisav. Prokrastineerimiskäitumist mõjutavad nii isikupõhised kui ka keskkondlikud tegurid, mis on omavahel dünaamiliselt seotud. Prokrastineerimist esineb sagedamini igavate, keerukate või ebameeldivate ülesannete puhul (Milgram et al., 1995) ning akadeemiline keskkond võib soodustada ka nende inimeste edasilükkamiskäitumist, kes oma igapäevaelulisi kohustusi tavaliselt edasi ei lükka (Moon \& Illingworth, 2005).

\section{Akadeemiline prokrastineerimine ja ennastjuhtiv õppimine põhikoolis}

Prokrastineerimine on eneseregulatsiooniprobleem (Steel, 2007), mis tõenäoliselt kujuneb välja koos ülejäänud õpiharjumustega. Põhikool on aeg, mil õpikeskkond muutub varasemaga võrreldes hüppeliselt keerukamaks, kuid samal ajal oodatakse õpilastelt vanuse kasvades üha suuremat iseseisvust ja vastutuse võtmist oma õpitegevuste planeerimise eest. Ennastjuhtiva õppimise arengu toetamist uurides on leitud, et põhikooliealiste laste peamine probleem on suutmatus oma aega planeerida, seega ka prokrastineerimine (Dembo \& Eaton, 2000). Uurimused kinnitavad üheselt, et enesejuhtimisoskused on õppimise kontekstis asendamatult olulised, kuid vähesed õpetajad analüüsivad õpilaste õppimisega seotud uskumusi, hoiakuid ja õpistrateegiate valikuid enne, kui kognitiivsed ja motivatsioonilised probleemid hakkavad äratuntavalt ópitulemustes ilmnema (Zimmerman, 2002). Paulitzki (2010) tugineb harjumuste kujunemise teooriatele (nt Neal, Wood, \& Quinn, 2006) ja osutab, et akadeemiline prokrastineerimine võib koolikonteksti muutumatus igapäevaolustikus hõlpsasti harjumuseks saada. Kuna harjumuslikud käitumismustrid on automatiseerunud ja neid on seetõttu raske muuta, on 
siinse artikli autorite meelest eriti oluline pöörata prokrastineerimiskäitumisele tähelepanu juba põhikoolieas.

\section{Akadeemiline prokrastineerimine ja õpetaja roll}

Paljud õpetajad eeldavad ekslikult, et enamik õpilasi omandab ennastjuhtivaks õppimiseks vajalikud kognitiivsed ja metakognitiivsed õpioskused iseenesest (Pintrich, 2002), ning on tõenäoline, et mõnel juhul on õpetaja jaoks keeruline tunda ära toetamist vajavaid ópioskusi. Osalt võib äratundmist raskendada asjaolu, et teatud vähetõhusad õpiharjumused ei pruugi õpitulemustes äratuntavalt avalduda. Näiteks võib õpilane oma koolitööd alati õigel ajal esitada, kuigi jätab óppimise alati viimasele hetkele ega realiseeri seetõttu oma täit potentsiaali. Samuti on näidatud, et õpetajad kalduvad omistama õppimisel esinevaid sisulisi probleeme erinevatele teguritele - olenevalt sellest, kas lapsel on ilmselged õpiraskused või mitte. Selliste atributsioonide tõttu saavad õpiraskustega õpilased tavakooli õpetajatelt enam tähelepanu, toetust ja abi kui selgete õpiraskusteta õpilased (Woolfson, Grant, \& Campbell, 2007).

Kuna akadeemiline prokrastineerimine leiab aset peamiselt koduseinte vahel ja põhikoolis, kus erinevate aineõpetajate iga üksiku õpilasega koos veedetav aeg on paratamatult piiratud, on õpetajal prokrastineerimisega seotud probleeme raske märgata, kui ta ei küsi lapselt spetsiaalselt selle kohta küsimusi. Õpetajaid koolitatakse küll märkama kliiniliselt määratletud õpiraskusi, kuid ebakohaste ópioskuste märkamine ja kohaste oskuste toetamine on sobilike ja lihtsalt kasutatavate hindamisvahendite puudumise tõttu raskendatud (Liu, 2009).

\section{Eesmärk ja hüpoteesid}

Siinses töös uurime, kuidas langevad kokku õpilaste hinnangud oma prokrastineerimiskäitumisele ning õpetajate hinnangud samade laste kalduvusele õpitegevustega viimase hetkeni viivitada. Prokrastineerimine võib toimuda varjatult ning prokrastineerijad võivad asju viimasele hetkele jättes siiski oma tööd õigel ajal ja nõuetele vastavalt esitada. Seetõttu oletame, et õpetajate ja laste hinnangud edasilükkamiskäitumisele ei pruugi alati kokku langeda. Uurimused õpetajate atributsioonide kohta (nt Woolfson et al., 2007) lubavad arvata, et õpetajad omistavad kohustuste jätmist viimasele hetkele pigem vähem võimekatele lastele, kelle õpitulemused võivad ebatõhusate õpioskuste tõttu enam kannatada. Võimekamate laste puhul ei pruugi õpetajad ajaplaneerimise ja prokrastineerimisega seotud probleeme märgata. Samuti oletame, et õpetajad 
kalduvad prokrastineerimisega kimpus olevate lastena pigem ära märkima klassiruumis enam silma paistvaid ehk ekstravertseid õpilasi ning neid õpilasi, kes on teistest vähem kohusetundlikud ehk vähem meelekindlad. Arvame, et õpetajate hinnangute ennustamisel on võrdväärselt tähtis koht nii lapse võimekusel kui ka eelnimetatud isiksuseomadustel. Tuginedes varasematele uurimustele, mis näitavad, et õpetajad peavad tüdrukuid poistest motiveeritumaks ja akadeemiliselt paremini toimetulevaks (nt Mullola et al., 2012), arvame, et õpetajad tunnevad ära pigem poiste prokrastineerimiskäitumise ja jätavad selle probleemi tüdrukute puhul märkamata.

\section{Meetod}

Valim

Õpilased. Õpilasi testiti aastatel 2007-2012 kahe laiapõhjalise haridusuuringu ${ }^{2}$ raames kokku viiel korral 3. klassist $\left(M_{\text {vanus }}=9,08 ; S D_{\text {vanus }}=0,37\right)$ kuni 5. klassini ning seejärel 7. ja 8. klassis. Uuringu põhivalimisse kuulus 551 eesti õppekeelega koolide õpilast (48,3\% poisid), kes vastasid 8. klassis prokrastineerimiskäitumist puudutavatele küsimustele. Üldise vaimse võimekuse ja isiksusedimensioonide keskmiste arvutamisel on kasutatud koguvalimi andmeid $\left(N_{\max }=767\right)$. Kõigi valimisse kuuluvate õpilaste vanemad olid andnud kirjaliku nõusoleku oma lapse osalemiseks uuringus.

Õpetajad. Uuringus osalesid valimisse kuuluvate õpilaste 8 . klassi matemaatika-, emakeele- ja ajalooõpetajad $(N=118)$. Õpetajad olid vanuses 23-72 (mediaan $=53)$.

\section{Hindamisvahendid}

Akadeemiline prokrastineerimine. Akadeemilise prokrastineerimise hindamiseks kasutasime enesekohast küsimustikku, mille adapteerisime spetsiaalselt põhikooliealistele lastele. Tuginesime kahele mõõdikule: Aitken Procrastination Inventory (Aitken, 1982; Ferrari, Johnson, \& McCown, 1995) ja Lay General Procrastination Scale (Lay, 1986). Valisime küsimustikest välja väited, mis oleksid põhikooli kontekstis asjakohased ja

2 „Eesti põhikooli efektiivsuse uuring” (2006-2009); „Üldpädevused ja nende hindamine” (2011-2014). 
õpilastele mõistetavad (nt „Viivitan koolitöödega alustamisega viimase minutini”, „Pean sageli viimasel hetkel pööraselt pingutama, et tähtajaks valmis jõuda"). Küsimustikku testisime esmalt pilootuuringuga üldvalimisse mittekuuluva Eesti kooli 6. klassi õpilaste seas $(N=15)$. Pilootuuringu järel jäi eestikeelsesse küsimustikku 19 väidet. Õpilased hindasid iga väite puhul, kuivõrd nad nõustuvad sellega viiepallisel Likert-tüüpi skaalal ( 1 = pole üldse nõus; 3 = raske öelda; 5 = täiesti nõus). Enesehinnangulise prokrastineerimiskäitumise võrdlemiseks õpetajate hinnangutega kasutasime töö analüüsides ainult neid väiteid, mis kajastasid sisuliselt kõige täpsemalt kohustuste täitmisega viivitamist ja nende jätmist viimasele hetkele (6 väidet). Töösse ei kaasatud näiteks väiteid hilinemise või koolitöödega alustamisega venitamise kohta. Konfirmatiivse faktoranalüüsi põhjal sobitusid andmed ühefaktorilise mudeliga hästi, $\chi^{2}(9)=20,1 ; p=0,02$; CFI $=0,98$, RMSEA $=0,047, n s$. Kõik standardiseeritud faktorlaadungid jäid vahemikku 0,54-0,75 ning olid statistiliselt olulised. Skaala sisereliaablus oli väga hea $(\alpha=0,81)$.

Õpetajate hinnangud ópilaste prokrastineerimiskäitumisele. Matemaatika-, ajaloo- ja emakeeleõpetajad hindasid kõiki uuringus osalevaid õpilasi erinevate omaduste alusel. Muu hulgas palusime õpetajatel märkida ära õpilased, kes jätavad koolitööde tegemise sageli viimasele minutile. Õpilane kuulus õpetajate hinnangul koolitöid viimasele hetkele jätvate laste rühma, kui vähemalt üks kolmest õpetajast oli lapse vastavas kategoorias ära märkinud, ning koolitöid viimasele hetkele mittejätvate õpilaste rühma, kui mitte ükski kolmest õpetajast polnud last vastavas kategoorias ära märkinud.

Üldine vaimne võimekus. Üldist vaimset võimekust hindasime Raveni progressiivsete maatriksitega (Raven, 1981; Eestis standardiseerinud Lynn, Allik, Pullmann, \& Laidra, 2004). Iga vastaja antud õige vastuse kodeerisime väärtusega üks, vale vastuse väärtusega null. Õigete vastuste summat käsitlesime üldise vaimse võimekuse skoorina. 3., 4. ja 5. klassis kasutasime Raveni D-osa ülesandeid (kokku 12 ülesannet) ning 7. ja 8. klassis laeefekti vältimiseks Raveni E-osa ülesandeid (kokku 12 ülesannet).

Isiksusedimensioonid. Isiksusedimensioonide hindamiseks kasutasime vaba vastuseformaadiga isiksuseküsimustikku SPIC2 (Arro, Kangro, \& Dulberg, 2011), mis on edasiarendus situatiivsest isiksuseküsimustikust lastele (SPIC, vt Arro, 2010) ning mis koosneb viiest situatsioonikirjeldusest. Küsimustik tugineb tänapäevasele juhtivale isiksusemudelile - viie 
faktori teooriale (Costa \& McCrae, 1992). Õpilastele esitatavad situatsioonikirjeldused on koostatud nii, et need seostuksid erinevate isiksusedimensioonidega: neurootilisuse / emotsionaalse stabiilsuse, ekstravertsuse/introvertsuse, avatuse/konventsionaalsuse, sotsiaalsuse/vaenulikkuse ja meelekindluse/minnalaskmisega. Näide situatsioonist on järgmine: „Kujutle järgmist olukorda: Sa said keeruka koduse ülesande aines, mis Sulle eriti ei meeldi. Proovid kodus ülesannet lahendada, aga see ei õnnestu. Mida Sa võiksid selles olukorras tunda? Kuidas Sa tegutseksid?” Õpilaste vabu vastuseid kodeerisid testi autorid vastavalt viie faktori teooria isiksusedimensioonide kirjeldustele, leides kokkulangevuse eelnimetatud iseennast kirjeldavate sõnade ja teoreetilise isiksusemudeli vahel. Isiksuseomaduste skoor moodustus vastaja nimetatud isiksusedimensiooni kategoriseeruvatest vastustest. Hindajatevahelise reliaabluse kontrollimiseks kodeerisid osa andmestikust mõlemad kodeerijad. Kõik ilmnenud erinevused kodeeringutes arutati läbi ning leiti sobiv isiksusekategooria.

Uurimuses kasutati kahe isiksusedimensiooni - ekstravertsuse/introvertsuse ja meelekindluse/minnalaskmise - vastuseid. Suuremad skoorid viitasid suhtarvuna rohkematele ekstravertsuse või meelekindlusega seostatavatele vastustele võrreldes kas introvertsuse või minnalaskmisega seostatavate väljenduste hulgaga.

\section{Protseduur}

Uuring korraldati 29 eesti õppekeelega kooli 45 klassis viiel aastal. Nii üldise vaimse võimekuse testile kui ka isiksuseomaduste mõõdikule ja prokrastineerimiskäitumise küsimustikule vastasid õpilased arvutis uurijate juhendamisel. Õpilastele selgitati, et uuringus osalemine on vabatahtlik ja nende vastused on konfidentsiaalsed. Üldine vaimne võimekus oli mõõdetud 3., 4., 5., 7. ja 8. klassis ning isiksuseseadumused 7. klassis. Prokrastineerimiskäitumist hindasid nii õpilased kui ka õpetajad 8. klassis.

\section{Andmeanalüiusi meetodid}

Õpilaste prokrastineerimiskäitumist mõõtva alamskaala faktorstruktuuri kontrollisime statistikapaketiga MPlus 6.0 (Muthén \& Muthén, 1998-2010) tehtud konfirmatiivse faktoranalüüsi abil. Õpilaste enesehinnangulise prokrastineerimise ja õpetajate hinnangute põhjal moodustuvate konfiguratsioonide sageduse kontrollimiseks kasutasime esimese järgu konfiguraalset sagedusanalüüsi (CFA), mis tehti programmiga SLEIPNER 2.1 (Bergman \& El-Khouri, 2002). CFA on $\chi^{2}$-analüüsi edasiarendus ning võimaldab võrrelda erinevaid kategoriaalsetel andmetel 
põhinevaid tulemusmustreid. Tulemused esitatakse sagedustabelina ning CFA kontrollib iga sagedustabeli lahtri puhul, kas mõõdetud sagedus erineb oluliselt ette antud tõenäosuste baasmudelil põhinevast oodatud sagedusest. Selle võrdluse tulemusel võivad erinevate konfiguratsioonide korral ilmneda tüübid või antitüübid, mida iseloomustab vastavalt kas oodatud esinemissagedusest oluliselt suurem (tüüp) või oluliselt väiksem (antitüüp) mõõdetud esinemissagedus (von Eye \& Gutiérrez Peña, 2004). Õpilaste enesehinnangulise prokrastineerimise ja õpetajate hinnangute põhjal moodustunud rühmade võrdlemiseks vaimse võimekuse ja isiksusedimensioonide alusel kasutasime dispersioonanalüüse (ANOVA) ning rühmakuuluvuse kõige olulisemate ennustajate väljaselgitamiseks logistilist regressioonanalüüsi, mis tehti statistikapaketiga SPSS 20.0.

\section{Tulemused}

\section{Õpetajate ja õpilaste hinnangute kokkulangevus}

Esmalt uurisime, kuivõrd langevad kokku õpilaste enesehinnang ja õpetajate hinnangud õpilaste prokrastineerimiskäitumisele. Selleks jaotasime õpilased enesehinnangulise prokrastineerimisküsimustiku keskmise tulemuse alusel kolme rühma (kirjeldavad statistikud on toodud tabelis 1). Kõige vähem prokrastineerivate laste rühma kuulusid õpilased, kelle koolitööde viimasele hetkele jätmise skoor oli kõigi küsimustiku täitnud laste keskmisest skoorist vähemalt 0,5 standardhälbe võrra väiksem $(<2,51)$. Enesehinnanguliselt kõige rohkem prokrastineerivate laste rühma kuulusid õpilased, kelle skoor oli kõigi küsimustiku täitnud laste keskmisest skoorist vähemalt 0,5 standardhälbe võrra suurem $(>3,31)$. Keskmiselt prokrastineerivate õpilaste hulka kuulusid ópilased, kelle kohustuste viimasele hetkele jätmise skoor jäi vahemikku 2,51-3,31.

Seejärel hindasime konfiguraalse sagedusanalüüsi (CFA) abil, kas mõned õpilaste ja õpetajate hinnangute kokkulangevuse kombinatsioonid esinevad oluliselt sagedamini või harvemini, kui juhuslikkuse alusel võiks eeldada. CFA tulemustes me statistiliselt olulisi tüüpe ega antitüüpe ei leidnud. See tähendab, et õpilasi jätkus eri rühmadesse juhusliku tõenäosusega ning ükski andmetes kajastuvatest kombinatsioonidest polnud oodatust sagedasem ega ka harvem. Erinevate kombinatsioonide esinemissagedused (nende erineva prokrastineerimiskäitumise rühma kuuluvate õpilaste arv, kelle õpetajad kas märkisid või ei märkinud kohustuste viimasele hetkele jätjaks) on toodud tabelis 2 . 
Tabel 1. Analüüsides kasutatavate tunnuste kirjeldavad statistikud

\begin{tabular}{l|c|c|c|c|c}
\hline & $\boldsymbol{N}$ & Min & Max & $\boldsymbol{M}$ & SD \\
\hline Akadeemiline prokrastineerimine & 551 & 1 & 5 & 2,91 & 0,80 \\
\hline Raven, 3. kl & 731 & 0 & 12 & 4,73 & 3,32 \\
\hline Raven, 4. kl & 767 & 0 & 12 & 5,98 & 3,21 \\
\hline Raven, 5. kl & 693 & 0 & 12 & 6,82 & 3,06 \\
\hline Raven, 7. kl & 607 & 0 & 12 & 3,12 & 2,60 \\
\hline Raven, 8. kl & 708 & 0 & 12 & 3,58 & 2,89 \\
\hline Ekstravertsus & 709 & 0 & 1 & 0,74 & 0,20 \\
\hline Meelekindlus & 681 & 0 & 1 & 0,73 & 0,21 \\
\hline
\end{tabular}

Märkus. Min = minimaalne tulemus; $\max =$ maksimaalne tulemus; $M=$ keskmine tulemus; $S D=$ standardhälve.

Tabel 2. Õpetajate hinnangute ja õpilaste enesehinnangulise prokrastineerimiskäitumise kokkulangevus

\begin{tabular}{l|c|c|c}
\hline \multirow{2}{*}{ Õpetaja hinnang } & \multicolumn{3}{|c}{ Õpilase enesehinnangulise prokrastineerimise määr } \\
\cline { 2 - 4 } & Madal & Keskmine & Kõrge \\
\hline $\begin{array}{l}\text { Ei jäta koolitöid viimasele } \\
\text { hetkele }\end{array}$ & $\begin{array}{c}105 \text { õpilast } \\
-/-\end{array}$ & 75 õpilast & $\begin{array}{c}81 \text { õpilast } \\
+/-\end{array}$ \\
\hline $\begin{array}{l}\text { Jätavad koolitööd viima- } \\
\text { sele hetkele }\end{array}$ & $\begin{array}{c}25 \text { õpilast } \\
-/+\end{array}$ & 34 õpilast & $\begin{array}{c}40 \text { õpilast } \\
+/+\end{array}$ \\
\hline
\end{tabular}

Märkus. $N=360 ;,-/{ }^{\prime \prime}$ kooskõlalised mitteprokrastineerijad, "-/+" vaid õpetaja hinnangul prokrastineerijad, "+/-" vaid enda hinnangul prokrastineerijad, "+/+" kooskõlalised prokrastineerijad. CFA kasutab analüüsides ainult neid isikuid, kelle puhul on olemas andmed kõigi analüüsitavate tegurite kohta.

\section{Kooskõlaliste ja mittekooskõlaliste prokrastineerijate erinevused vaimses võimekuses ja isiksusedimensioonides}

Üldine vaimne võimekus. Kontrollimaks hüpoteesi, et õpetajad jätavad prokrastineerimiskäitumise keskmisest võimekamate õpilaste puhul pigem märkamata, kasutasime dispersioonanalüüse (ANOVA). Võrdlesime kooskõlalisi prokrastineerijaid („+/+”) ja mitteprokrastineerijaid („-/-”) vaid enese („+/-") ja vaid õpetaja („-/+") hinnangul prokrastineerijatega alates 3. klassist mõõdetud üldise vaimse võimekuse alusel.

Neisse rühmadesse kuuluvate õpilaste üldine vaimne võimekus erines statistiliselt oluliselt kõigis klassides mõõdetud tulemuste alusel: 3. klassis 
$(F(3,175)=8,47, p<0,001), 4$. klassis $(F(3,186)=5,14, p<0,01), 5$. klassis $(F(3,194)=9,93, p<0,001), 7$. klassis $(F(3,202)=4,49, p<0,01)$ ja 8 . klassis $(F(3,242)=2,91, p<0,05)$. Selleks, et hinnata, milliste konkreetsete rühmade tulemused erinesid, kasutasime post hoc-analüüsidena Tukey testi (kui hinnatava tunnuse variatiivsus rühmades vastas Levene'i testi alusel homogeenuskriteeriumi nõuetele) ja Games-Howelli testi (kui variatiivsuse nõuet oli rikutud). Tulemused kinnitasid, et õpetajate hinnangul prokrastineerivate õpilaste (rühmad „+/+” ja „-/+”) vaimse võimekuse tase (mõõdetud Raveni testiga) oli üldjuhul järjepidevalt madalam õpetaja hinnangul mitteprokrastineerivate õpilaste (rühmad "-/-” ja „+/-") vaimsest võimekusest, olenemata sellest, kas lapsed endi hinnangul prokrastineerisid või mitte. Statistiliselt olulised erinevused on täpsemalt esitatud tabelis 3 ja joonisel 1.
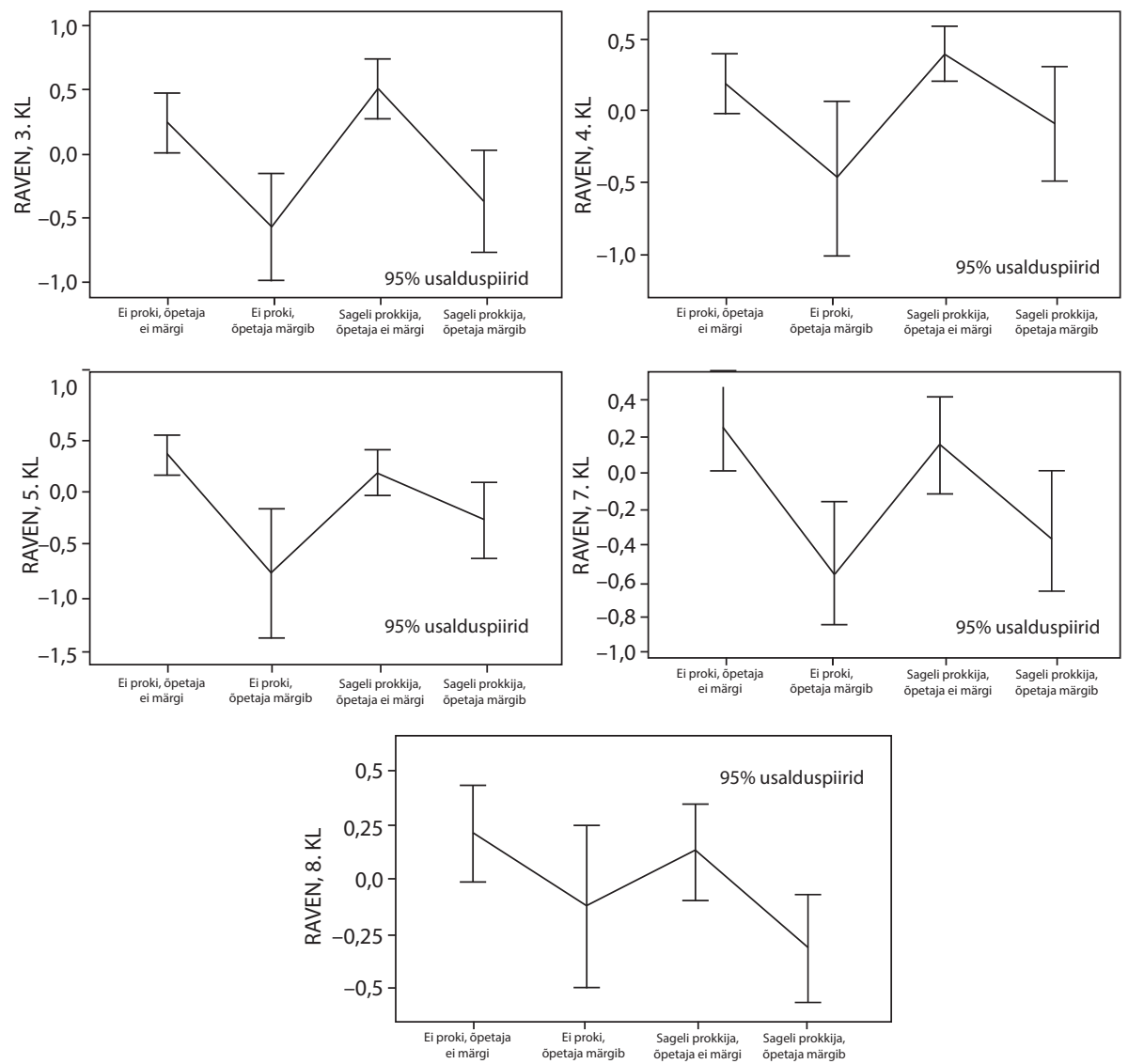

Joonis 1. ANOVA tulemused: kooskõlaliste prokrastineerijate ja mitteprokrastineerijate ning vaid enese ja vaid õpetaja hinnangul prokrastineerijate võrdlus üldise vaimse võimekuse alusel. Joonistel on esitatud Raveni standardiseeritud skoorid 
Isiksusedimensioonid. Selleks, et hinnata, kas õpetajatel on kergem ära tunda klassis pigem rohkem silma paistvate laste prokrastineerimiskäitumist ning kas lapsed, keda õpetajad prokrastineerijateks ei märgi, on keskmiselt kohusetundlikumad kui need õpilased, kelle puhul on ka õpetaja nende venitamiskalduvust märganud, võrdlesime rühmi dispersioonanalüüside abil kahe isiksusedimensiooni - ekstravertsuse ja meelekindluse - alusel.

Rühmad erinesid statistiliselt oluliselt nii ekstravertsuse $(F(3,237)=$ $3,65, p<0,05)$ kui ka meelekindluse poolest $(F(3,235)=7,16, p=<0,001)$. Teistega võrreldes olid ekstravertsemad need õpilased, kes hindasid end ise prokrastineerijateks ja keda ka õpetajad olid prokrastineerijatena nimetanud. Meelekindluses ilmnesid erinevused pigem enda hinnangul prokrastineerivate õpilaste ja mitteprokrastineerijate vahel, mitte õpetajate märgitud või märkimata õpilasrühmade vahel (vt tabel 3 ja joonis 2).
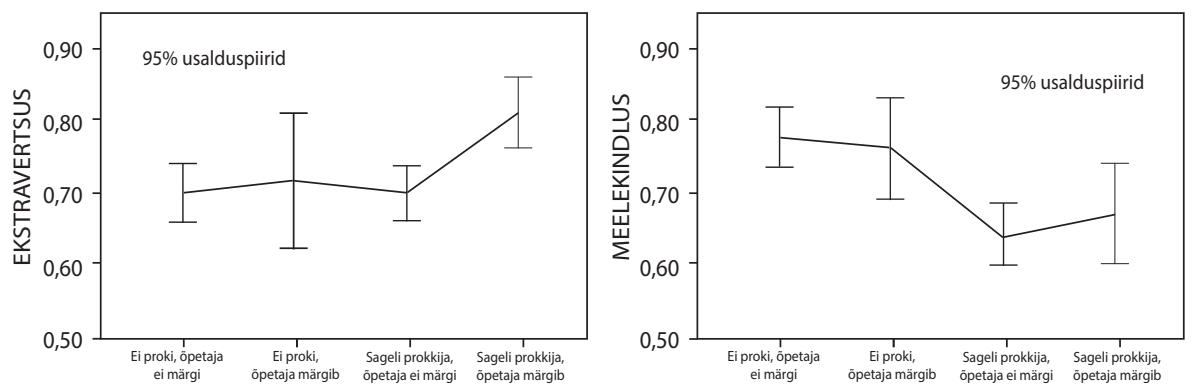

Joonis 2. ANOVA tulemused: kooskõlaliste prokrastineerijate ja mitteprokrastineerijate ning vaid enese ja vaid õpetaja hinnangul prokrastineerijate võrdlus ekstravertsuse ja meelekindluse alusel 
Tabel 3. Kooskõlalisi prokrastineerijaid ja mitteprokrastineerijaid ning vaid enese ja vaid õpetaja hinnangul prokrastineerijaid iseloomustava üldise vaimse võimekuse ja kolme isiksusedimensiooni kirjeldavad statistikud ning rühmadevaheline võrdlus

\begin{tabular}{|c|c|c|c|c|c|c|c|c|c|}
\hline & \multicolumn{2}{|c|}{$\begin{array}{c}-/- \\
\text { (rühm 1) }\end{array}$} & \multicolumn{2}{|c|}{$\begin{array}{c}-/+ \\
\text { (rühm 2) }\end{array}$} & \multicolumn{2}{|c|}{$\begin{array}{c}+/- \\
\text { (rühm 3) }\end{array}$} & \multicolumn{2}{|c|}{$\begin{array}{c}+/+ \\
\text { (rühm 4) }\end{array}$} & \multirow[t]{2}{*}{ * } \\
\hline & $M$ & $S D$ & $M$ & $S D$ & $M$ & $S D$ & $M$ & $S D$ & \\
\hline \multicolumn{10}{|l|}{ Võimekus } \\
\hline Raven, 3. kl & 5,52 & 3,41 & 2,82 & 2,67 & 6,38 & 2,92 & 3,52 & 3,27 & $\begin{array}{l}2<1 ; 3 \\
4<1 ; 3\end{array}$ \\
\hline Raven, 4. kl & 6,59 & 2,89 & 4,50 & 3,50 & 7,28 & 2,37 & 5,75 & 3,19 & $2<3$ \\
\hline Raven, $5 . \mathrm{kl}$ & 7,90 & 2,53 & 4,50 & 3,71 & 7,40 & 2,41 & 6,00 & 3,04 & $\begin{array}{c}2<1 ; 3 \\
4<1\end{array}$ \\
\hline Raven, 7. kl & 3,80 & 2,93 & 1,80 & 1,90 & 3,55 & 2,85 & 2,29 & 2,44 & $\begin{array}{c}2<1 ; 3 \\
4<1\end{array}$ \\
\hline Raven, 8. kl & 4,20 & 3,24 & 3,24 & 2,60 & 3,95 & 2,81 & 2,68 & 2,13 & $4<1,3$ \\
\hline \multicolumn{10}{|l|}{ Isiksus } \\
\hline Ekstravertsus & 0,70 & 0,20 & 0,72 & 0,23 & 0,70 & 0,17 & 0,81 & 0,15 & $4>1,3$ \\
\hline Meelekindlus & 0,77 & 0,22 & 0,76 & 0,17 & 0,64 & 0,18 & 0,67 & 0,22 & $1>3,4$ \\
\hline
\end{tabular}

Märkus. „,/-" kooskõlalised mitteprokrastineerijad, „,/+" vaid õpetaja hinnangul prokrastineerijad , $+/-"$ vaid enda hinnangul prokrastineerijad ${ }_{, \prime}+/+$ " kooskõlalised prokrastineerijad.

* Dispersioonanalüüside post hoc-analüüsidel põhinevad statistiliselt olulised erinevused rühmade vahel ( $p<0,05$, rühmade numbriliste tähistuste seletused on tabeli esimesel real).

\section{Õpetajate hinnangut ennustavate tegurite võrdlus enese hinnangul sagedasti prokrastineerivate õpilaste puhul}

Selleks, et hinnata, millised tegurid ennustavad enesehinnanguliste prokrastineerijate puhul kõige tugevamalt, kas ka õpetaja neid prokrastineerijateks peab, kasutasime logistilist regressioonanalüüsi. Ennustasime õpilaste jagunemist kahte rühma: enese hinnangul prokrastineerivad õpilased, kelle ka õpetajad märkisid prokrastineerijaks („+/+”), ning enese hinnangul prokrastineerivad õpilased, keda õpetajad prokrastineerijatena ei nimetanud („+/-”). Ennustajatena kaasasime regressioonimudelisse õpilaste soo, 3. klassis mõõdetud üldise vaimse võimekuse ${ }^{3}$ ja 7 . klassis

3 3. klassis mõõdetud vaimne võimekus eristas muudel aastatel mõõdetud vaimse võimekuse näitajatega võrreldes rühmi „+/+" ja „+/-" kõige selgemalt, $t(80)=4,01, p<0,001$. 
mõõdetud ekstravertsuse. Kuna meelekindlus dispersioonanalüüside järgi rühmi ei eristanud, siis seda mudelisse ei kaasatud.

Kogu kirjeldatud regressioonimudel võimaldas pärast kahe marginaalse juhtumi (outlier'i) eemaldamist õigesti klassifitseerida 81,6\% õpilastest. Üksikute ennustavate tunnuste analüüsil ilmnes, et statistiliselt olulised rühmakuuluvuse ennustajad olid Wald-statistiku tõenäosuse alusel nii 3. klassis mõõdetud üldine vaimne võimekus kui ka 7. klassis mõõdetud ekstravertsus. Õpilase sugu ei avaldanud õpetaja nimetatud ja nimetamata jäetud prokrastineerijate eristamisele statistiliselt olulist mõju. Tõenäosus, et õpilane kuulus õpetaja märgitud prokrastineerijate hulka, oli negatiivselt seotud üldise vaimse võimekusega. Mida kõrgem oli lapse võimekuse tase 3. klassis, seda väiksem oli tõenäosus, et ta kuulus 8. klassis õpetaja märgitud prokrastineerijate hulka. Tõenäosus, et õpilane kuulus õpetaja märgitud prokrastineerijate hulka, oli positiivselt seotud ekstravertsusega. Mida ekstravertsem oli laps 7. klassis, seda suurem oli tõenäosus, et ta kuulus 8. klassis õpetaja märgitud prokrastineerijate hulka.

Tabel 4. Õpetaja ja õpilaste hinnangute lahknevust või kokkulangemist ennustavad tegurid enese hinnangul sagedasti prokrastineerivate õpilaste puhul

\begin{tabular}{l|c|c|c|c|c}
\hline Ennustajad & $B$ & $S E(B)$ & Wald & $p$ & $e^{B}$ \\
\hline Sugu & $-0,80$ & 0,64 & 1,59 & 0,21 & 0,45 \\
\hline Üldine vaimne võimekus 3. klassis & $-1,37$ & 0,37 & 13,45 & $<0,001$ & 0,25 \\
\hline Ekstravertsus 7. klassis & $-1,08$ & 0,43 & 6,25 & $<0,05$ & 2,93 \\
\hline Konstant & $-1,32$ & 0,48 & 7,54 & $<0,01$ & 0,27 \\
\hline$X^{2}$ & \multicolumn{5}{|c}{26,6} \\
\hline$d f$ & \multicolumn{5}{|c}{3} \\
\hline
\end{tabular}

Märkus. $e^{B}$ - eksponentsiaal- $B ; d f$ - vabaduseastmete arv.

\section{Arutelu}

Mitmekülgset teavet erinevate õpioskuste kohta ja nende paindlikku kasutamist erinevates õppimissituatsioonides võib pidada üheks efektiivset õppimist iseloomustavaks tunnuseks. Õpetaja üks keskseid ülesandeid koolis peaks olema õpioskuste toetamine ja arendamine, mis eeldab nii toetamist vajavate õpioskuste äratundmist kui ka arusaama, mis omadused või osaoskused võiksid olla efektiivsete õpioskuste kujunemise eelduseks. 
Ennastjuhtiva õppimise teooria kohaselt tuleks põhikoolis õpioskuste arengut aktiivselt toetada, sest suurem osa lapsi ei jõua sobilike ja efektiivsete ópioskuste teadvustamise ning kasutamiseni ilma vanemate või õpetajate juhendamise ja toetuseta (Pintrich, 2002). Kuna õppimine on suuresti individuaalne protsess, võiks oletada, et mõningatel juhtudel on keeruline teada, mil viisil iga konkreetne õpilane koduses keskkonnas õpib. Seetõttu uurisimegi, kas õpetajad oskavad märgata probleeme ühe spetsiifilise õppimisega seotud käitumise - prokrastineerimise - kontekstis. Selleks hindasime, kas õpilaste enda hinnang prokrastineerimiskäitumisele vastab õpetaja hinnangule lapse kohta. Tulemustest ilmnes, et õpetaja ja õpilase hinnang prokrastineerimiskäitumisele ei ühti alati, näiteks eristub rühm lapsi, kes näevad iseend prokrastineerijatena, kuid õpetajate meelest neil ajakasutusega probleeme ei ole.

Mõistmaks, millega on seotud erinevused õpetajate ja õpilaste hinnangute vahel ning millised võivad olla prokrastineerimiskäitumist maskeerivad tegurid, analüüsisime eri rühmadesse kuuluvate õpilaste individuaalseid erinevusi. Ehkki varasemad uurimused on kinnitanud, et eriti naissoost õpetajate arvates on just poisid enam õppimise ja käitumise reguleerimisega hädas (nt Mullola et al., 2012), ei leidnud meie soolisi erinevusi puudutav hüpotees kinnitust. Sagedaste prokrastineerijate hulgas, keda õpetajad prokrastineerijatena nimetasid, polnud poisse oluliselt rohkem kui tüdrukuid.

Oletasime $\mathrm{ka}$, et õpetajatel on raskem ära tunda nende õpilaste prokrastineerimiskäitumist, kelle üldise vaimse võimekuse tase on kõrge. Leidsime, et tõepoolest kaldusid õpetajad õpilaste õppimisega viivitamist alahindama vaimselt võimekamate ja ülehindama vaimselt vähem võimekamatel lastel. See suundumus oli järjepidev ja jälgitav 3.-8. klassini mõõdetud vaimse võimekuse puhul. Ristlõikelistes korrelatiivse loomuga uurimustes on prokrastineerimise ja vaimse võimekuse seos peaaegu olematu, see tähendab, et prokrastineerijaid leidub võrdselt nii võimekate kui ka vähem võimekate hulgas (Ferrari et al., 1995). Prokrastineerimiskäitumise sagedasemat esinemist võimekamate tudengite puhul on meile teadaolevalt põgusalt käsitletud vaid mõnes üksikus uurimuses (nt Aitken, 1982). Seetõttu on saadud tulemus väga huvitav ja suunab prokrastineerimiskäitumise arengulisi suundumusi kognitiivse võimekuse võtmes edasi uurima.

Praktilise külje pealt osutavad meie uurimuse tulemused asjaolule, et selliste varjatud ja komplekssete omaduste hindamisel, nagu seda kodutööde tegemiseks kasutatavad õpioskused ilmselt on, teevad õpetajad järeldusi õpilaste tugevate ja nõrkade külgede kohta neile kättesaadava 
info, näiteks hinnete või akadeemilise soorituse põhjal. Võimekamad õpilased, kes tulevad akadeemiliselt hästi toime ka puudulikest õpioskustest hoolimata, võivad probleemsemate õpilaste kõrval õpetajate tähelepanu alt välja jääda. Vaimse võimekuse tähtsust õpetajate hinnangute eristamisel võib võrrelda Woolfsoni ja kolleegide (2007) järeldustega õpetajate atributsioonide kohta õpiraskustega laste õppimisvõime hindamisel ning see osutab võimalusele, et õpetajad omistavad õpiraskusi peamiselt neile õpilastele, kelle puhul need selgelt õpitulemustes kajastuvad. Kaudselt võib siin peituda ka üks vastus küsimusele, miks Eesti kontekstis kerkib ikka ja jälle probleemina esile andekate õpilaste potentsiaali mitterealiseerumine (Sepp, 2012). Võib olla, et osa võimekaid õpilasi pole omandanud kohaseid õpioskusi ega oska oma õppimisprotsessi efektiivselt suunata.

Puudujääke õpioskustes võivad maskeerida ka õpilaste isiksuseomadused. Uurimusest järeldub, et õpetajatel on raskem ära tunda introvertsemaid ehk klassiruumis tõenäoliselt teistest vähem silma paistvaid prokrastineerijaid. Teisalt võivad õpetajad arvata, et lastel, kes on teistest elavamad, on enam raskusi enda käitumise ja õppimisprotsessi reguleerimisega, mistõttu nad peavad selliseid ópilasi ka kohustuste viimasele hetkele jätjateks. Tulemust võib interpreteerida ka õpilaste ja õpetajate suhteid käsitlevate uurimuste valguses (Rudasill \& RimmKaufman, 2009; Zee, Koomen, \& van der Veen, 2013), mille kohaselt seostub õpilaste ekstravertsus oluliselt nii õpetajate ja õpilaste vahelise konfliktsuse kui ka lähedusega. Õpetajate suhted häbelike ja tagasihoidlike lastega on küll vähem konfliktsed, kuid samas ka vähem lähedased, mistõttu võivad tagasihoidlike laste probleemid jääda märkamata.

Seos märkamatuks jääva prokrastineerimise ja isiksuseomaduste vahel, mis teatud kombinatsioonis võivad kohanemist pigem mitte toetada, võib viidata vajadusele õpioskusi senisest põhjalikumalt hinnata - õpioskusega seotud probleemid jäävad ehk märkamata õpilaste puhul, kes end eriti märkama ei sunni, mis aga ei tähenda, et õpilaste areng oleks võimetekohaselt toetatud.

Uurimusel on ka mõned piirangud. Kuna õpilaste prokrastineerimiskäitumist hinnati enesehinnangulise skaalaga ning reaalse edasilükkamiskäitumise kohta puuduvad andmed, on võimalik, et teatud juhtudel võis õpetajate ja õpilaste hinnangute lahknevus tuleneda reaalse õpikäitumise tahtlikul või tahtmatul moonutamisel õpilaste enesepeegeldustes. Nii näiteks on võimalik, et mõni õpilane peab end prokrastineerijaks, kuigi ta seda tegelikult pole, või siis vastupidi, õpilane ei pruugi osata oma õpikäitumist adekvaatselt hinnata ega selliseid probleeme märgata. Näiteks ei pruugi õpetajahinnanguliste prokrastineerijate rühm peegeldada mitte 
õpetaja ekslikku hinnangut, vaid hoopis seost õpilaste väikese võimekuse, väikese eneserefleksioonioskuse ja õpilase mittetajutud prokrastineerimise vahel - õpetaja märkab lapse õpikäitumises probleemi, kuid laps ise ei oska end prokrastineerijaks pidada. Samuti tuleb juhtida tähelepanu asjaolule, et õpetaja hinnang õpilaste prokrastineerimiskäitumisele põhines vaid ühel väitel. Üheväiteliste mõõtevahendite kasutamisel on nii eeliseid (nt vastaja töökoormuse vähendamine) kui ka ohte (võimalikud mõõtmisvead). Peame ühe väite kasutamist praegusel juhul piisavalt usaldusväärseks, sest hinnatav konstrukt puudutab õpilaste väga konkreetset käitumist, mitte näiteks mõne abstraktsema omaduse (nt meelekindluse) hindamist (Robins, Hendin, \& Trzesniewski, 2001). Siiski tunnistame, et laiemate üldistuste tegemisel tuleb olla ettevaatlik.

\section{Kokkuvõte}

Õppimine ja kohaste õpioskuste kasutamine võib olla raske nii õpilastele, kelle tulemused ja käitumine ühelegi õpiraskusele otseselt ei viita, kui ka õpilastele, kes on ilmselgelt õppimisega kimpus. Meie tulemused näitavad, et õpilaste hulgas on lapsi, kes on enese hinnangul prokrastineerijad, kuid kelle puhul õpetajad probleemi ei teadvusta. Kuna neid õpilasi eristas teistest õpilastest läbivalt kõrgem üldise vaimse võimekuse tase, peame vajalikuks võimekuse ja prokrastineerimiskäitumise vahelisi arengusuundumusi edaspidi kindlasti põhjalikumalt uurida. Sama moodi nagu Liu (2009) ning Dembo ja Eaton (2000), rõhutame ka meie, et õpetajad vajavad õpioskuste arengu süsteemsemaks toetamiseks valiidseid ja usaldusväärseid hindamisvahendeid, mis aitavad neil üheskoos õpilastega õpipädevuse arendamiseks olulisi tegureid teadvustada ja õpioskuste puudujääke võimalikult varakult märgata. Sellega saab koolikeskkonnas tagada, et vajalikku tuge pakutakse kõigile õpilastele, ka neile, kelle puhul on siiani tundunud, et nad seda ei vaja. Lisaks peaksid õpetajad sarnaselt traditsioonilise aineõppega oskama püstitada konkreetseid õpipädevuse õpieesmärke ning valdama asjakohaseid õpetamismeetodeid. Dembo ja Eaton (2000) rõhutavad, et puudujäk̈ke eneseregulatsioonis ei tohiks kasutada õpilaste kehva soorituse põhjendusena, sest tegelikkuses on ka eneseregulatsioon ja ennastjuhtiv õppimine oskused, mida saab ja tuleb õpilastele koolis õpetada. 


\section{Tänusõnad}

Uurimus valmis osaliselt Euroopa Sotsiaalfondi egiidi all loodud käitumis-, sotsiaal- ja terviseteaduste doktorikooli toetatava interdistsiplinaarse projekti „Kohustuste irratsionaalne edasilükkamine: ennustavad tegurid ja võimalikud tagajärjed” ning osaliselt Eesti Haridus- ja Teadusministeeriumi tellitud projekti „Üldpädevused ja nende hindamine” (S10012) toel. Artikli kirjutamist on toetanud Eesti Teadusagentuur (grant IUT03-03). Täname kõiki uuringus osalenud õpetajaid ja õpilasi.

\section{Kasutatud kirjandus}

Aitken, M. E. (1982). A personality profile of the college student procrastinator (Doctoral dissertation). ProQuest Information \& Learning.

Arro, G. (2010). Children's self-reflection and personality and their relationships with cognitive ability and academic success. In A. Toomela (Ed.), Systemic personoriented study of child development in early primary school (pp. 225-245). Switzerland: Peter Lang.

Arro, G., Kangro, E.-M., \& Dulberg, J. (2011). Situatiivne isiksusetest lastele (SPIC2). Avaldamata käsikiri.

Bergman, L. R., \& El-Khouri, B. M. (2002). SLEIPNER: A statistical package for pattern-oriented analyses. Version 2.1. Stockholm: Stockholm University. Retrieved from http://w3.psychology.su.se/sleipner/.

Costa, P. T., Jr., \& McCrae, R. R. (1992). Four ways five factors are basic. Personality and individual differences, 13(6), 653-665.

http://dx.doi.org/10.1016/0191-8869(92)90236-I

Dembo, M. H., \& Eaton, M. J. (2000). Self-regulation of academic learning in middlelevel schools. The Elementary School Journal, 100(5), 473-490. http://dx.doi.org/10.1086/499651

DeWitte, S., \& Schouwenburg, H. C. (2002). Procrastination, temptations, and incentives: The struggle between the present and the future in procrastinators and the punctual. European Journal of Personality, 16(6), 469-489. http://dx.doi.org/10.1002/per.461

Ferrari, J. R. (2000). Procrastination and attention: Factor analysis of attention deficit, boredomness, intelligence, self-esteem, and task delay frequencies. Journal of Social Behavior \& Personality, 15(5), 185-196.

Ferrari, J. R., Johnson, J. L., \& McCown, W. G. (1995). Procrastination and task avoidance: Theory, Research, and Treatment. New York: Plenum Press. http://dx.doi.org/10.1007/978-1-4899-0227-6

Ferrari, J. R., \& Pychyl, T. A. (2012). „If I wait, my partner will do it”: The role of conscientiousness as a mediator in the relation of academic procrastination and perceived social loafing. North American Journal of Psychology, 14(1), 13-24. 
Grunschel, C., Patrzek, J., \& Fries, S. (2013). Exploring reasons and consequences of academic procrastination: An interview study. European Journal of Psychology of Education, 28(3), 841-861. http://dx.doi.org/10.1007/s10212-012-0143-4

Howell, A. J., Watson, D. C., Powell, R. A., \& Buro, K. (2006). Academic procrastination: The pattern and correlates of behavioural postponement. Personality and Individual Differences, 40(8), 1519-1530. http://dx.doi.org/10.1016/j.paid.2005.11.023

Klassen, R. M., Ang, R. P., Chong, W. H., Krawchuk, L. L., Huan, V. S., Wong, I. Y., \& Yeo, L. S. (2009). A cross-cultural study of adolescent procrastination. Journal of Research on Adolescence, 19(4), 799-811. http://dx.doi.org/10.1111/j.1532-7795.2009.00620.x

Lay, C. H. (1986). At last, my research article on procrastination. Journal of Research in Personality, 20(4), 474-495. http://dx.doi.org/10.1016/0092-6566(86)90127-3

Lay, C. H. (1994). Trait procrastination and affective experiences: Describing past study behavior and its relation to agitation and dejection. Motivation and Emotion, 18(3), 269-284. http://dx.doi.org/10.1007/BF02254832

Liu, O. L. (2009). Evaluation of a learning strategies scale for middle school students. Journal of Psychoeducational Assessment, 27(4), 312-322. http://dx.doi.org/10.1177/0734282908327935

Lynn, R., Allik, J., Pullmann, H., \& Laidra, K. (2004). Sex differences on the progressive matrices among adolescents: Some data from Estonia. Personality and Individual Differences, 36(6), 1249-1255. http://dx.doi.org/10.1016/S0191-8869(02)00240-4

Merriam-Webster, http://www.merriam-webster.com/dictionary/procrastinate.

Milgram, N. A., Dangour, W., \& Ravi, A. (1992). Situational and personal determinants of academic procrastination. The Journal of General Psychology, 119(2), 123-133. http://dx.doi.org/10.1080/00221309.1992.9921166

Milgram, N., Marshevsky, S., \& Sadeh, C. (1995). Correlates of academic procrastination: Discomfort, task aversiveness, and task capability. The Journal of Psychology, 129(2), 145-155. http://dx.doi.org/10.1080/00223980.1995.9914954

Milgram, N., Mey-Tal, G., \& Levison, Y. (1998). Procrastination, generalized or specific, in college students and their parents. Personality and Individual Differences, 25(2), 297-316. http://dx.doi.org/10.1016/S0191-8869(98)00044-0

Moon, S. M., \& Illingworth, A. J. (2005). Exploring the dynamic nature of procrastination: A latent growth curve analysis of academic procrastination. Personality and Individual Differences, 38(2), 297-309. http://dx.doi.org/10.1016/j.paid.2004.04.009

Mullola, S., Ravaja, N., Lipsanen, J., Alatupa, S., Hintsanen, M., Jokela, M., \& Keltikangas-Järvinen, L. (2012). Gender differences in teachers' perceptions of students' temperament, educational competence, and teachability. British Journal of Educational Psychology, 82(2), 185-206. http://dx.doi.org/10.1111/j.2044-8279.2010.02017.x

Muthén, L. K., \& Muthén, B. O. (1998-2010). Mplus user's guide (6th ed.). Los Angeles: Muthén \& Muthén.

Neal, D. T., Wood, W., \& Quinn, J. M. (2006). Habits - a repeat performance. Current Directions in Psychological Science, 15(4), 198-202. http://dx.doi.org/10.1111/j.1467-8721.2006.00435.x 
Paulitzki, J. (2010). Procrastination as self-regulatory failure: Habitual avoidance and inhibitory control moderate the intention-behaviour relation for unpleasant tasks (Doctoral dissertation). University of Waterloo, Canada.

Pintrich, P. R. (2002). The role of metacognitive knowledge in learning, teaching, and assessing. Theory into Practice, 41(4), 219-225. http://dx.doi.org/10.1207/s15430421tip4104_3

Rabin, L. A., Fogel, J., \& Nutter-Upham, K. E. (2011). Academic procrastination in college students: The role of self-reported executive function. Journal of Clinical and Experimental Neuropsychology, 33(3), 344-357.

http://dx.doi.org/10.1080/13803395.2010.518597

Raven, J. (1981). Manual for Raven's progressive matrices and Mill Hill vocabulary skills. Oxford Psychologists Press.

Robins, R. W., Hendin, H. M., \& Trzesniewski, K. H. (2001). Measuring global self-esteem: Construct validation of a single-item measure and the Rosenberg Self-Esteem Scale. Personality and Social Psychology Bulletin, 27(2), 151-161. http://dx.doi.org/10.1177/0146167201272002

Rothblum, E. D., Solomon, L. J., \& Murakami, J. (1986). Affective, cognitive, and behavioral differences between high and low procrastinators. Journal of Counseling Psychology, 33(4), 387-394. http://dx.doi.org/10.1037/0022-0167.33.4.387

Rudasill, K. M., \& Rimm-Kaufman, S. E. (2009). Teacher-child relationship quality: The roles of child temperament and teacher-child interactions. Early Childhood Research Quarterly, 24(2), 107-120. http://dx.doi.org/10.1016/j.ecresq.2008.12.003

Schraw, G., Wadkins, T., \& Olafson, L. (2007). Doing the things we do: A grounded theory of academic procrastination. Journal of Educational Psychology, 99(1), 12-25. http://dx.doi.org/10.1037/0022-0663.99.1.12

Sepp, V. (2012). Täppisteadustest - pauguga ja pauguta. Postimees, 03.07.2012. Külastatud aadressil http://arvamus.postimees.ee/895438/viire-sepp-tappisteadustest-pauguga-ja-pauguta.

Sirois, F. M. (2007). "I'll look after my health, later”: A replication and extension of the procrastination-health model with community-dwelling adults. Personality and Individual Differences, 43(1), 15-26.

http://dx.doi.org/10.1016/j.paid.2006.11.003

Solomon, L. J., \& Rothblum, E. D. (1984). Academic procrastination: Frequency and cognitive-behavioral correlates. Journal of Counseling Psychology, 31(4), 503-509. http://dx.doi.org/10.1037/0022-0167.31.4.503

Steel, P. (2007). The nature of procrastination: A meta-analytic and theoretical review of quintessential self-regulatory failure. Psychological Bulletin, 133(1), 65-94. http://dx.doi.org/10.1037/0033-2909.133.1.65

Steel, P. (2010). The procrastination equation: How to stop putting things off and start getting stuff done. Random House Digital.

Steel, P., \& Ferrari, J. (2013). Sex, education and procrastination: An epidemiological study of procrastinators' characteristics from a global sample. European Journal of Personality, 27(1), 51-58. http://dx.doi.org/10.1002/per.1851

Zee, M., Koomen, H. M., \& van der Veen, I. (2013). Student-teacher relationship quality and academic adjustment in upper elementary school: The role of student personality. Journal of School Psychology, 51(4), 517-533.

http://dx.doi.org/10.1016/j.jsp.2013.05.003 
Zimmerman, B. J. (2002). Becoming a self-regulated learner: An overview. Theory into Practice, 41(2), 64-70. http://dx.doi.org/10.1207/s15430421tip4102_2

Tice, D. M., \& Baumeister, R. F. (1997). Longitudinal study of procrastination, performance, stress, and health: The costs and benefits of dawdling. Psychological Science, 8(6), 454-458. http://dx.doi.org/10.1111/j.1467-9280.1997.tb00460.x

Van Eerde, W. (2003). A meta-analytically derived nomological network of procrastination. Personality and Individual Differences, 35(6), 1401-1418. http://dx.doi.org/10.1016/S0191-8869(02)00358-6

Von Eye, A., \& Gutiérrez Peña, E. (2004). Configural frequency analysis: The search for extreme cells. Journal of Applied Statistics, 31(8), 981-997. http://dx.doi.org/10.1080/0266476042000270545

Wolters, C. A. (2003). Understanding procrastination from a self-regulated learning perspective. Journal of Educational Psychology, 95(1), 179-187. http://dx.doi.org/10.1037/0022-0663.95.1.179

Woolfson, L., Grant, E., \& Campbell, L. (2007). A comparison of special, general and support teachers' controllability and stability attributions for children's difficulties in learning. Educational Psychology, 27(2), 295-306.

http://dx.doi.org/10.1080/01443410601066826 


\title{
No deed goes unnoticed? Associations between teachers' noticing academic procrastination and individual differences in students
}

\author{
Kati Ausa $^{\text {a }}$, Grete Arro ${ }^{a}$, Anna-Liisa Jõgi ${ }^{\text {ab }}$, Elina Malleus ${ }^{a}$ \\ a Tallinn University, Institute of Psychology \\ $b$ Tallinn University, Institute of Educational Sciences
}

\begin{abstract}
Summary
Academic procrastination - delaying studying or leaving schoolwork to the very last minute - is regarded as a self-regulation failure (Steel, 2007) that will most likely interfere with learning success earlier than previous studies suggest. It is reasonable to assume that procrastination behaviour will already be acquired along with other study habits during middle school, although most research on academic procrastination has been carried out among college students. Academic procrastination differs from time management or simple delaying, as the definition of procrastination is wider, explicitly incorporating some sort of motivational conflict (Paulitzki, 2010). Procrastinators have difficulties carrying out their plans and intentions, on account of which procrastination can in general be characterised as an irrational and unintentional self-defeating behaviour that can be regarded as a typical self-regulation failure (Steel, 2007). It has been shown that procrastination occurs more frequently with boring, complicated or unpleasant (aversive) tasks (Milgram et al., 1995), and that academic contexts can induce procrastination even for people who usually do not delay their everyday tasks (Moon \& Illingworth, 2005).

The transition from primary to middle school entails learning material that is more complex and abstract as well as students being held more responsible for their own learning. That means that self-regulatory skills become increasingly important and academic success is associated more and more with the use of adaptive study skills. Teachers can support students in mastering the necessary study skills as long as they are able to recognise the skills that need supporting. Many teachers make the mistake of assuming that most of their students acquire necessary cognitive and metacognitive study strategies without explicit guidance (Pintrich, 2002) and it is likely that in some cases it is difficult for the teachers to even recognise the skills that would need supporting.
\end{abstract}


To some extent, recognising ineffective study strategies might be tricky, as they might not be directly visible in learning results. For example, a student might always present his/her schoolwork on time, while having done all the work at the last possible moment and hence not realizing his full potential. Procrastination in academic contexts occurs mostly in the private home environment, and in middle school, and the time that different teachers spend with each and every student is inevitably restricted. Consequently, teachers have trouble noticing problems with procrastination without specifically probing the students about it. Teachers are trained to recognise clinically relevant learning difficulties, but noticing, assessing and correcting ineffective study strategies is problematic because of the lack of valid and easy-to-use methods, not only in Estonia, but also elsewhere (Liu, 2009).

Based on the above, we asked whether eighth grade teachers $(N=118)$ can spot difficulties with students' study strategies in the context of procrastination. We were interested to see whether eighth grade students' $(N=551)$ evaluations of their procrastination would coincide with teachers' evaluations of the child's behaviour. To that end, we formed three groups of children based on their own assessment of their procrastination frequency and compared their self-assessment results to the evaluations of their teachers. The results point to the fact that children's and teachers' evaluations do not always overlap. For example, we found a group of children who consider themselves frequent procrastinators, but are not considered as such by their teachers.

In order to understand what possible factors might play a role in the mismatch between teachers' and students' evaluations, or in other words, what might be the factors that mask students' procrastination tendencies from the eyes of the teachers, we analysed the effect of the different cognitive and personality indicators in students. The students belonging to the current sample have participated in longitudinal educational studies since they were in the third grade. Hence, we could assess their general ability measured by Raven Progressive Matrixes from grades three, four, five, seven and eight and their extraversion and conscientiousness scores from grade seven in order to see whether those factors differ among procrastinators and non-procrastinators whom teachers either recognise or do not recognise as procrastinators. We used ANOVA and logistic regression analyses and found that teachers are more likely to report students who have a relatively low general mental ability as procrastinators, regardless of whether the students consider themselves as procrastinators or not. The trend was consistent and apparent for ability- 
levels from the third to the eighth grade. Teachers also were more likely to report students who were more extraverted (or less introverted) than their peers as procrastinators.

As the association between procrastination and general cognitive abilities has been found to be almost non-existent in cross-sectional studies (Ferrari et al., 1995, pp. 41) - procrastinators can be found among low and high ability students (Ferrari, 2000) - and as more frequent procrastination has been reported among more able students only very casually in a few studies (i.e. Aitken, 1982), the results are intriguing and suggest giving further attention to discovering trends in the development of procrastination.

For practical matters, the current results refer to the possibility that when assessing the quality of such hidden and complex phenomena as homework related study strategies, teachers tend to base their conclusions on student strengths and weaknesses and on information that is easily attainable, i.e., students' temperament or academic and graded performance. We assume that teachers have difficulties in recognising self-regulatory problems, especially among more able students, as they might not be reflected in school performance. One of the teachers' main responsibilities in school should be supporting the development of the students' learning strategies, which on the one hand, implies the ability to recognise deficient strategies and also knowledge about attributes or skills that could be the prerequisites for the development of effective learning strategies. In addition to skills and methods for assessing students' subject knowledge, teachers would also benefit from knowledge and valid instruments for assessing and supporting students' more hidden and implicit learning strategies.

In conclusion, learning and using adequate learning strategies can pose difficulties for students who explicitly struggle in academic contexts, but also for students whose deficient study habits, masked by high general cognitive ability, do not explicitly point to the relevance of any learning difficulties. Our results show that there is a group of able students admitting to the vice of procrastination, who are not perceived as problematic by their teachers. We conclude that although cognitive abilities might not show straightforward associations with procrastination, the mediating effect of cognitive abilities can have detrimental effects on the development of adaptive study habits.

Keywords: academic procrastination, learning strategies, teacher evaluations of learning strategies, general cognitive ability, personality 